\title{
Cytotoxicity of Heavy Metals to A Thyroid Carcinoma Cell Line
}

\section{Jun Kobayashi*, Keiichi Ikeda² and Hideo Sugiyama ${ }^{3}$}

${ }^{1}$ Faculty of Veterinary Medicine, Nippon Veterinary and Life Science University, Tokyo, Japan

${ }^{2}$ Faculty of Pharmaceutical Sciences, Hokuriku University, Ishikawa, Japan

${ }^{3}$ Graduate School of Health Sciences, Matsumoto University, Nagano, Japan

\begin{abstract}
Multiple heavy metals are known to cause renal insufficiency and necrosis, details on the toxic mechanism are still lacking. We investigated the cytotoxicity of 12 heavy metals to the $8505 \mathrm{C}$ thyroid cancer cells at concentrations of $10^{-3}-10^{5} \mu \mathrm{M}$. Notable decreases in cell viability were observed in exposures to four metals in the divalent cation form (nickel, copper, zinc, and cadmium) at concentrations $\geq 1 \mu \mathrm{M}$. The effect of cadmium on cell death was substantial. In addition, the toxicity of $3 \mu \mathrm{M}$ cadmium to the cells was inhibited by the addition of high concentrations $(300 \mu \mathrm{M})$ of calcium or selenium, but intracellular levels of cadmium increased.
\end{abstract}

\section{Keywords: Cell death; Cadmium; Toxicity}

\section{Introduction}

Environmental chemical pollutants are present in the atmosphere, water and soil, and many are known to exert direct effects on the human body. Many of the mechanisms of pollutant action are still incompletely understood. Multiple heavy metals can cause renal insufficiency and necrosis [1,2]. Although such illnesses are considered to be related to the action of proteins such as a metallothionein and to depend on the form of metal involved [2-4], details on the toxic mechanism are still lacking.

An epidemiological investigation conducted in Japan's Hokuriku district in the 1990s reported that hypertrophy and deterioration of thyroid function can occur with high frequency in cadmium-polluted areas [5]. The Jinzu river in Toyama prefecture, where Itai-itai disease is prevalent, is known to have been contaminated with high concentrations of cadmium, a metal reported to exert effects on the thyroid gland [6], although the mechanism by which cadmium exerts its toxicity is not completely understood. We previously observed that cadmium was still detected in environmental waters in the Hokuriku district [7]. Understanding the mechanism and effects of cadmium toxicity is an ongoing avenue of investigation in public health.

In this study, we assessed the cytotoxicity of heavy metals, including cadmium, to human thyroid cancer cells.

\section{Materials and Methods}

\section{Reagents and apparatus}

We were supplied a cultured thyroid cancer cell line (8505C) from the Cell Resonance Center for Biomedical Research of Tohoku University, and used for all experiments. Heavy metals can exert effects on the thyroid gland [8]. Cells were cultured in RPMI-1640 medium (Sigma-Aldrich, St. Louis, MO, USA) with 10\% fetal bovine serum (FBS, Difco, BD Biosciences, Franklin Lakes, NJ, USA) and antibiotics (100 $\mu \mathrm{g} / \mathrm{mL}$ streptomycin and $100 \mathrm{U} / \mathrm{mL}$ penicillin, Wako Pure Chemical Industries, Osaka, Japan; biochemistry grade). For cell stripping, we used $0.25 \%$ trypsin in $1 \mathrm{mM}$ Ethylenediaminetetraacetic acid (EDTA) (Gibco, Carlsbad, CA, USA). Modified RPMI-1640 (phenol red-free, Sigma-Aldrich) was used for all experiments without FBS. Cell viability was assessed using 3-(4,5-dimethyl-2-thiazolyl)-2,5-diphenyl-2 $\mathrm{H}$ tetrazorium bromide (MTT, Dojindo Laboratories, Kumamoto, Japan). Standard metal solutions were prepared by dissolving magnesium chloride, aluminum chloride, calcium chloride, manganese chloride, nickel sulfate, copper (II) sulfate, zinc chloride, cadmium nitrate, tin (II) chloride, lead nitrate, potassium permanganate, and sodium selenate or sodium selenite (all of special grade, Wako Pure Chemical Industries) in ultrapure water which had been autoclaved for sterilization. All other reagents used were of commercially available special grade.

Laboratory glassware and 24-well plates (Iwaki Glass, Tokyo, Japan; bottom area of well: $1.9 \mathrm{~cm}^{2}$ ) were used for cell cultures and experiments. Ultrapure water was prepared by the Elix/Milli-Q Element system (Merck-Millipore, Billerica, MA, USA; specific resistance value $\geq 18 \mathrm{M} \Omega \cdot \mathrm{cm}$ ). Atomic absorption spectrometry (AAS; Z-8000, Hitachi, Ibaraki, Japan) was used for determining cadmium concentrations.

\section{Procedure}

Cells were cultured in $5 \% \mathrm{CO}_{2}$ in a $37^{\circ} \mathrm{C}$ incubator to a subconfluent state, and stripped from the culture plate with trypsin/EDTA. The medium was replaced after centrifuging at $800 \mathrm{rpm}$ for $5 \mathrm{~min}$, and the cells were resuspended at a typical concentration $\left(5 \times 10^{4}\right.$ cells $\left./ \mathrm{mL}\right)$. One milliliter of the cell suspension was placed in each well of a 24-well plate. After overnight incubation, the medium supernatant was replaced with the modified medium, and $1 \mu \mathrm{L}$ of a standard metal $\left(10^{-3}-10^{5} \mu \mathrm{M}\right)$ and/or carboxylic anion solution (acetate, citrate, and EDTA; $10^{-3}-10^{5}$ $\mu \mathrm{M}$ ) of suitable concentration was added. After $24 \mathrm{~h}$, cell viability was assessed using the MTT assay and cadmium concentration was measured by AAS.

The MTT assay was performed as follows: The supernatant was removed from all wells, leaving $0.5 \mathrm{~mL}$ of culture medium per well. MTT reagent $(50 \mu \mathrm{L}, 2 \mathrm{mg} / \mathrm{mL}$ aqueous solution) was added to each well, and the plate was incubated for $2 \mathrm{~h}$. The plate was then centrifuged at 2,000 $\mathrm{rpm}$ for $15 \mathrm{~min}$, and the residual metabolite of the MTT reagent was dissolved in $250 \mu \mathrm{L}$ of dimethyl sulfoxide after complete removal

${ }^{*}$ Corresponding author: Jun Kobayashi, School of Veterinary Nursing and Technology, Faculty of Veterinary Medicine, Nippon Veterinary and Life Science University, 1-7-1 Kyonan-cho, Musashino, Tokyo 180-8602, Japan, Tel: +81422314151; Fax: +81422332094; E-mail: junkoba@nvlu.ac.jp

Received March 21, 2017; Accepted April 26, 2017; Published April 29, 2017

Citation: Kobayashi J, Ikeda K, Sugiyama H (2017) Cytotoxicity of Heavy Metals to A Thyroid Carcinoma Cell Line. J Environ Anal Toxicol 7: 461. doi: 10.4172/2161 0525.1000461

Copyright: @ 2017 Kobayashi J, et al. This is an open-access article distributed under the terms of the Creative Commons Attribution License, which permits unrestricted use, distribution, and reproduction in any medium, provided the original author and source are credited. 
of the supernatant. The relative number of live cells was determined by measuring the absorbance at $550 \mathrm{~nm}$. All measurements were repeated for at least three replicates, and the trend was confirmed independently.

Intracellular and extracellular cadmium concentrations were measured as follows: The cells were stripped from the 24-well plate with trypsin/EDTA and the cell suspension was transferred to a separate tube. After centrifugation (13,000 rpm, $5 \mathrm{~min})$, the supernatant was transferred to another tube and used to quantify extracellular cadmium levels; the remaining cells were fragmented by sonication, and the lysis was used for quantifying intracellular cadmium levels. All experiments were performed in triplicate at one time, and subsequently repeated.

\section{Results and Discussion}

\section{Strategy}

Cell culture conditions were examined prior to the actual experiments. Dulbecco's modified Eagle's medium (DMEM)/10\% FBS and RPMI-1640/10\% FBS were previously reported as suitable for culturing $8505 \mathrm{C}$ cells $[8,9]$. Since metals in the medium and FBS are expected to affect culture conditions, their levels in the media were determined beforehand. We elected to use RPMI-1640/10\% FBS because it contained lower levels of metals and FBS.

As phenol red is known to exert an estrogenic and chelating effect, modified RPMI-1640, free of phenol red, was used. Moreover, FBS contains ingredients necessary for cell growth, such as amino acids, and may therefore skew cell viability experiments. Accordingly, an FBS-free medium was used during the experiments.

Complete cell adhesion occurred approximately $4 \mathrm{~h}$ after cell dispersion, as observed by microscope. The experiment was conducted 1 day later as a precaution. The number of cells and the reaction time used in the experiment were $5 \times 10^{4}$ cells/well and $24 \mathrm{~h}$, respectively, taking into account the sensitivity of the MTT method, the area of cell adhesion (the rate at which cells adhere and occupy the bottom of the well), and the proliferation rate. The time for cell doubling by division was 2 to 3 days, and the time to confluence was approximately 1 week (with 10\% FBS). Therefore, if cells are not affected by metals, their numbers should not change substantially over the first $24 \mathrm{~h}$.

\section{Effect of heavy metals and carboxylic anions on cell viability}

Cell death was observed at concentrations of $1 \mu \mathrm{M}$ or higher for nickel, copper, zinc, and cadmium (nickel: Approximately 20\% death at $100 \mu \mathrm{M}$ and $50 \%$ at $300 \mu \mathrm{M}$; copper: $20 \%$ at $10 \mu \mathrm{M}$ and $90 \%$ at 30 $\mu \mathrm{M}$; zinc: $40 \%$ at $30 \mu \mathrm{M}$ and $45 \%$ at $100 \mu \mathrm{M}$; Cd: $25 \%$ at $1 \mu \mathrm{M}$ and $80 \%$ at $0.3 \mu \mathrm{M})$. As cadmium had the greatest negative effect on cell survival, a more detailed investigation of cadmium was performed. When high-concentration (0.1-1,000-fold) magnesium, aluminum, calcium, magnesium, tin, and lead were combined with cadmium, rates of cell death decreased (Figure 1). Furthermore, low-concentration $(1 \mu \mathrm{M})$ cadmium was assessed in the presence of aluminum, calcium, selenate, selenite, and EDTA $(10$ or $100 \mu \mathrm{M})$ with respect to cadmium's cellular uptake. When combined with aluminum, cadmium was not found in either the supernatant or the cultured cells (totally about $10 \%)$. When combined with EDTA, cadmium was found only in the supernatant, largely at the concentration added. When calcium, selenate, or selenite were combined with cadmium, cadmium was found in both the supernatant and the cell lysis (in approximate compositions of $50 \%+20 \%, 90 \%+10 \%$ and $60 \%+30 \%$, respectively). When cadmium and selenite were combined, the concentration of cadmium in the supernatant and cell lysis was almost identical to its concentration when no selenite was added, but in the presence of calcium and selenite, cadmium concentration decreased in the supernatant and increased in the cell lysis (Figure 2).

Generally, toxicity of metals results from accumulating cellular levels. However, our findings show that although cadmium exposure resulted in cell death following uptake, its accumulation in cells was less toxic, perhaps as a result of a change in its chemical form. We hypothesize that cadmium toxicity was mitigated in these experiments because of co-precipitation with the hydroxides of aluminum, tin, and lead, which was observed visually in the case of the latter two metals. EDTA is considered to block cadmium invasion of cells by a chelation effect. However, cadmium has been reported to block calcium metabolism, and to bind competitively with calcium [10]. Although selenium can be toxic, it has been shown to protect against cadmium toxicity.

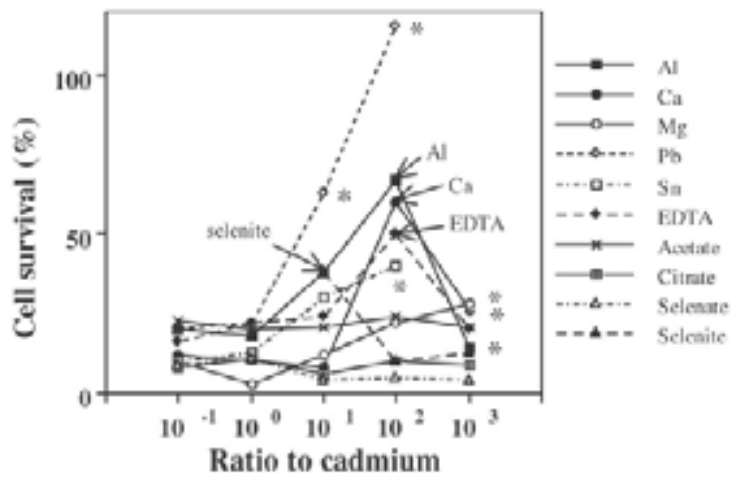

Figure 1: Effects of cationic metals and anions on cadmium toxicity to cultured cells. Human thyroid cancer cells (8505C) were treated with cadmium ( $3 \mu \mathrm{M})$. Other compounds were added and are shown as relative ratios to the cadmium concentration. Metals other than aluminum and calcium were precipitated $\left(^{*}\right)$ at high concentrations, preventing MTT detection. High cell survival rates with no precipitation were seen for aluminum, calcium, EDTA, and selenite (arrows) Al: Aluminum; Ca: Calcium; EDTA: Ethylenediaminetetraacetic Acid.

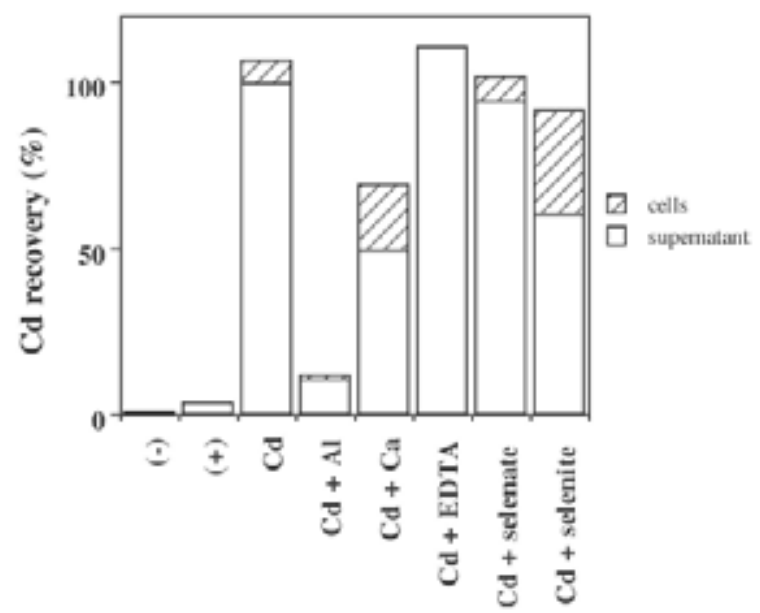

Figure 2: Cadmium (Cd) recovery from the medium supernatant and cultured cells. Cells were treated with cadmium $(1 \mu \mathrm{M})$ and $10 \mu \mathrm{M}$ (selenate and selenite) or $100 \mu \mathrm{M}$ (aluminum, calcium, and EDTA), based on the results presented in Figure 1 (arrows). Symbols: (-): medium only; (+): cells+medium; Cd: Cadmium+cells+medium; Al: Aluminum; Ca: Calcium; Mg: Magnesium; $\mathrm{Pb}$ : Lead; Sn: Tin; EDTA: Ethylenediaminetetraacetic Acid. 
Citation: Kobayashi J, Ikeda K, Sugiyama H (2017) Cytotoxicity of Heavy Metals to A Thyroid Carcinoma Cell Line. J Environ Anal Toxicol 7: 461. doi: 10.4172/2161-0525.1000461

In the present study, even when calcium was present at high concentrations, cell death by calcium alone was not observed, and only a mitigation of the toxic effect of cadmium was seen. Toxicity was mitigated more weakly by selenite, and selenite itself exhibited weak toxicity. We hypothesize that their mechanisms of action differ.

Future work should address why the decreased toxicity of cadmium which was seen with selenite was not seen with selenate, and how calcium and selenite affected cadmium toxicity.

\section{References}

1. Wada O (1985) Kinzoku to hito -Ecotoxicology to rinsho (Metal elements and human beings, with emphasis of clinical ecotoxicology). Asakura Shoten, Tokyo.

2. Ishido M, Kunimoto $M(2001)$ Regulation of cell fate by cadmium and zinc. J Heal Sci 47: 9-13.

3. Min KS, Sano E, Ueda H, Sakazaki F, Yamada K, et al. (2015) dietary deficiency of calcium and/or iron, an age-related risk factor for renal accumulation of cadmium in mice. Biol Pharm Bull 38: 1557-1563.
4. Jia Y, Wang L, Qu Z, Wang C, Yang Z (2017) Effects on heavy metal accumulation in freshwater fishes: species, tissues, and sizes. Environ Sci Pollut Res Int 24: 9379-9386.

5. Nishijo M, Nakagawa H, Morikawa Y, Tabata M, Senma M, et al. (1994) A study of thyroid hormone levels of inhabitants of the cadmium-polluted Kakehashi river basin. Jpn J Hyg 49: 598-605.

6. Chung HK, Nam JS, Ahn CW, Lee YS, Kim KR (2016) Some elements in thyroid tissue are associated with more advanced stage of thyroid cancer in Korean women. Biol Trace Elem Res 171: 54-62.

7. Yamagami T, Ezaki T, Moriguchi J, Fukui Y, Okamoto S, et al. (2006) Low-leve cadmium exposure in Toyama city and its surroundings in Toyama prefecture Japan, with references to possible contribution of increase urinary cadmium levels. Sci Total Environ 362: 56-67.

8. Park KS, Kim JB, Bae J, Park SY, Jee HG, et al. (2012) Berberine inhibited the growth of thyroid cancer cell lines 8505C and TPC1. Yonsei Med J 53: 346-351.

9. Hong JM, Park CS, Nam-Goong IS, Kim YS, Lee JC, et al. (2014) Curcumin enhances docetaxel-induced apoptosis of $8505 \mathrm{c}$ anaplastic thyroid carcinoma cells. Endocrinol Metab (Seoul) 29: 54-61.

10. Li P, Zhao C, Zhang Y, Wang X, Wang J, et al. (2016) Calcium alleviates cadmium-induced inhibition on root growth by maintaining auxin homeostasis in Arabidopsis seedlings. Protoplasma 253: 185-200. 